\title{
Agencia infantil situada. Un análisis desde las experiencias de niñas y niños que trabajan en contextos de desigualdad social en Argentina
}

Children's agency located. An analysis from the experiences of girls and boys working in contexts of social inequality in Argentina

\author{
Laura Frasco Zuker ${ }^{1, \|}$ \\ https://orcid.org/0000-0002-8328-7267 \\ laurefz@gmail.com \\ Rocío Fatyass ${ }^{\text {III, IV }}$ \\ https://orcid.org/0000-0003-1879-5828 \\ rociofatyass@gmail.com \\ Valeria Llobet ${ }^{1, \text { II }}$ \\ https://orcid.org/0000-0003-0673-8260 \\ valeria.s.llobet@gmail.com
}

I Consejo Nacional de Investigaciones Científicas y Técnicas - Buenos Aires, Argentina

" Universidad Nacional de San Martín - San Martín, Buenos Aires, Argentina

III Consejo Nacional de Investigaciones Científicas y Técnicas - Villa María, Córdoba, Argentina

IV Universidad Nacional de Villa María - Villa María, Córdoba, Argentina 


\title{
Resumen
}

El trabajo realizado por niñas y niños es uno de los fenómenos que articulan preocupaciones sobre las infancias en América Latina y su análisis ha dado lugar a fructíferos debates que exceden las perspectivas abolicionistas y regulacionistas. El objetivo de este artículo es contribuir a este campo de estudios con nuevas preguntas y matices a partir del análisis comparativo de experiencias de investigación con niñas y niños que venden, piden y cuidan en contextos de desigualdad en Argentina. Sostenemos que aún en condiciones de subalternidad se despliegan formas de agencia infantil que es preciso analizar de manera situada.

Palabras clave: infancia; agencia; trabajo infantil; cuidado.

\begin{abstract}
The work done by girls and boys is one of the phenomena that articulate concerns about childhood in Latin America and its analysis has given rise to fruitful debates that exceed abolitionist and regulatory perspectives. The objective of this article is to contribute to this field of studies with new questions and nuances from the comparative analysis of research experiences with girls and boys who sell, ask and care in contexts of inequality in Argentina. We maintain that even under conditions of subalternity, forms of child agency are deployed, which requires precise analysis.
\end{abstract}

Keywords: childhood; agency; child labour; care. 


\section{Introducción}

El trabajo realizado por niñas y niños es uno de los fenómenos que articulan preocupaciones sobre las infancias en América Latina (Llobet, 2012) y ha dado lugar a fructíferos debates tales como la relación entre el trabajo infantil y la protección de derechos, las formas en que la desigualdad afecta a los hogares y hasta qué punto el trabajo infantil es sólo una estrategia de sobrevivencia.

Los estudios socioantropológicos han mostrado cómo los sentidos y efectos del trabajo infantil resultan indisociables del contexto en el que ocurren, de la consideración de la heterogeneidad de las infancias en términos de diversidad cultural y de los condicionantes institucionales que impiden y/o dificultan su erradicación.

La propia definición de trabajo infantil provoca posiciones encontradas en el campo académico y en el espacio social general, así como "actitudes" (Novick; Campos, 2007) frente a este fenómeno que suelen girar entre perspectivas abolicionistas y regulacionistas. Si bien dichos enfoques aportan discusiones centrales, muchas veces operan como obstáculos epistemológicos (Bachelard, 1987) que impiden aprehender la complejidad de la temática. Sea por su condena moral o bien porque romantizan el aporte social y económico de niñas y niños, estos enfoques invisibilizan las lógicas de conflicto y de poder de las cuales ellas y ellos son partícipes.

Ahora bien, la producción académica sobre el tema abarca un amplio conjunto de temáticas que dan cuenta de las múltiples dimensiones que compromete el objeto de estudio (Macri; Uhart, 2012). En línea con ello, el objetivo de este artículo es contribuir con nuevas preguntas y matices analíticos a un campo de debates sobre infancias, trabajo y desigualdad, enfocando esta preocupación desde las propias experiencias infantiles y desde la capacidad de agencia de niñas y niños incluso en condiciones de subalternidad. Dicho recorte se fundamenta en que las vivencias de niñas y niños aportan pistas que deben ser tenidas en cuenta para reponer el carácter complejo del trabajo infantil. A partir de datos obtenidos en nuestros trabajos de campo sobre infancias, trabajo y cuidado, buscamos interpelar algunos supuestos sobre el trabajo de niñas y niños de clases populares.

Por lo tanto, recuperamos estudios del campo de la infancia en pos de problematizar estas prácticas desde procesos de investigación en contextos de pobreza urbana y periurbana en dos provincias argentinas, Córdoba y Misiones. 


\section{Trabajo realizado por niñas/os: hacia un abordaje relacional}

Las distintas miradas en torno al trabajo infantil suponen ciertas concepciones sobre la niñez (Rausky, 2009a) así como respecto al trabajo. Partiendo de la base del carácter histórico y socialmente situado de estas categorías, consideramos que un análisis realizado desde las ciencias sociales debe colocar la mirada no solamente en la descripción de las diversas actividades laborales desarrolladas por niñas y niños sino también preguntarse por sus condiciones de producción y realización.

Esto significa interrogar sobre las tramas de prácticas, relaciones y sentidos, siempre situados. Así es menester definir una y otra vez la categoría de trabajo (Gorbán, 2014), en especial el trabajo llevado a cabo por niñas y niños, ampliamente diseminado y, a la vez, encubierto. El/la niño/a productivo/a (Llobet, 2012) no es un sujeto aislado sino que se compromete en una serie relaciones sociales complejas que involucran espacios, tiempos e interacciones intergeneracionales particulares que es preciso reconocer en nuestros análisis.

En concordancia con los estudios sobre infancias trabajadoras y en nuestros propios trabajos de campo en contextos de pobreza, admitimos que el trabajo no se agota en la reflexividad económica de la acción y no está dirigido únicamente a la obtención de recursos materiales (Salles, 1999). Como recuerda Marx (2017), el trabajo va más allá de una dimensión puramente económica e involucra otros aspectos antropológicos y sociales tales como el principio de movimiento, de creación y de transformación de la realidad que gobiernan la actividad del trabajo, así como la capacidad activa del sujeto, la expresión de sus habilidades físicas y mentales y la posibilidad de perfección. Este punto, lo que Marx llamó trabajo verdadero evidencia que, bajo determinadas condiciones, el trabajo no es un mero medio para la producción de mercancías sino un fin en sí mismo, lo que da cuenta de la realización del sujeto en tanto agente social.

Teniendo presente estos señalamientos para pensar nuestros propios estudios de caso, nos parece importante mencionar que incluso bajo condiciones de producción como las capitalistas, el trabajo infantil no suprime las posibilidades de que niñas y niños encuentren márgenes de agencia en la realización del trabajo. Ahora bien, ¿qué entendemos por agencia? La capacidad creativa e inventiva de la práctica, un tipo de presión contra lo estructurado para la obtención de recursos (desigualmente distribuidos) y/o ante la falta de 
reconocimiento y autoridad, que puede ser más o menos reflexiva o disposicional y que deja rastros en el discurso y en el cuerpo del agente en el intento de producir un cambio en un sistema de relaciones (Fatyass, 2020).

Pensar la agencia en este sentido en investigaciones sobre y con niñas y niños implica tomar en consideración que pueden realizar una serie compleja y variada de tareas, así como también regular y controlar (con ciertas limitaciones) su propia acción y su intercambio con la naturaleza (en el sentido marxista) y con otros (sean adultas/os, jóvenes o niñas/os). La agencia de niñas y niños enmarcada desde las cuestiones del trabajo y el cuidado significa el impulso de las prácticas infantiles (no siempre emancipatorias) por demandar otros cursos en relaciones estructurales de desigualdad.

Dichas relaciones estructurales no elegidas, parafraseando a Marx, son pasibles de ser modificadas por los sujetos sociales. Tomando esta idea como disparadora, creemos que niñas y niños también deben ser considerados como sujetos definidos por aquello que hacen y a su vez por aquello que los demás y las circunstancias hacen sobre sus experiencias. Por eso resaltamos y examinamos su capacidad de agencia en tanto agentes que trabajan, es decir, producen valor en el mundo que habitan y no por ello descuidamos las condiciones en las que lo hacen.

En este punto, ¿qué se entiende específicamente por trabajo infantil? La Organización Internacional del Trabajo (OIT) lo ha definido como "toda actividad económica y/o estrategia de supervivencia, remunerada o no, realizada por niñas y niños, por debajo de la edad mínima de admisión al empleo o trabajo (16 años)" (Ministerio de Trabajo, Empleo y Seguridad Social, 2020). Esto incluye, tal como señalan Rausky y Leyra Fatou (2017), la producción por parte de niñas y niños de bienes y servicios, el limosneo y su participación en actividades domésticas cuando: a) un niño/a deba dedicar todo su tiempo a dichas tareas viéndose privado de la posibilidad de ir a la escuela, situación en la que se considera a estas actividades como equivalentes a una actividad económica o b) cuando las tareas productivas familiares no pueden ser distinguidas de aquellas relativas a la reproducción familiar, porque el lugar en que se realizan aquellas y el lugar de habitación coinciden, o porque los ámbitos de producción y reproducción social están involucrados. Se trata entonces de una categoría clasificatoria destinada a otorgar legibilidad y administratividad a un conjunto heterogéneo de actividades y prácticas (Scott, 1998). 
Esta mirada de la OIT se vuelve especialmente problemática cuando al evidenciar las condiciones de trabajo infantil -en el ámbito familiar o fuera de él- éstas son definidas a priori como "malas condiciones" e "insanas". Así, las estrategias de niñas y niños que trabajan (y de sus familias) en contextos de desigualdad social, suelen ser criminalizadas y estigmatizadas. Desde aquí, la perspectiva abolicionista de la OIT sobre el trabajo infantil, parte de esencializar el carácter del sujeto infantil como aquel que sólo juega y es dependiente en la resolución de la vida, así como romantizan los ambientes en los que se debe criar y cuidar a niñas y niños, reduciendo la capacidad de estas/os a realizar tareas llamadas de "baja intensidad" y con escasa significatividad social. Así, se aceptan solamente algunas expresiones de trabajo doméstico (como tender la cama) bajo el rótulo de "child work" y se rechaza, bajo cualquier circunstancia, lo que usualmente se define como "child labour", en tanto es considerado trabajo "duro" (cf. Liebel; Saadi, 2011).

Si bien las clasificiaciones mencionadas complejizan la categoría de trabajo y tienen por objeto la protección de la infancia, es necesario avanzar hacia una mirada relacional que no se restrinja a los aspectos negativos (y muchas veces descontextualizados) del trabajo infantil, sino que además pueda colocar preguntas acerca de cuáles son las necesidades que busca cubrir la/el niña/o y la unidad doméstica, cuáles son las expectativas de niñas y niños, qué estrategias despliegan para concretarlas, en el marco de qué relaciones sociales tales tareas son desarrolladas, qué efectos producen con las mismas y qué margen de negociación hallan niñas y niños en las restricciones objetivas.

Para no invisibilizar estos aspectos, ni encasillar la problemática, resulta clave incorporar un análisis detenido sobre las experiencias y las perspectivas infantiles que desafíe la visión convencional (y legalista) establecida (Milstein, 2006). En este punto coincidimos con Leibel y Saadi cuando afirman que: "las medidas para la protección a los niños de las peores formas de trabajo infantil sirven a menudo implícitamente para legitimar las limpiezas sociales en áreas de gente rica, de negocios o proyectos turísticos" (Liebel; Saadi, 2011, p. 114). De este modo, afirmamos que, para ampliar el enfoque de derechos sobre la infancia, es necesario conocer sin prejuicios cómo viven, sienten y resuelven sus condiciones de existencia niñas y niños. Ello conlleva el riesgo de caer en una postura ingenua (muchas veces encubierta de progresismo académico) sobre las condiciones de desigualdad o explotación en las que se anudan esas 
estrategias. Así, sostenemos que comprender el nivel de la práctica también demanda introducir críticamente el nivel estructural de la acción.

En esta dirección, los Nuevos Estudios del Trabajo Latinoamericanos que estructuran el campo de debate contemporáneo de la sociología y de la antropología del trabajo en la región, señalan que conviven una diversidad de formas de trabajo: 1) trabajo asalariado, que puede darse en condiciones de explotación; 2) trabajo no clásico, no industrial, no asalariado, no formal y no protegido, lo que expresa una forma de sujeto laboral ampliado (De la Garza Toledo, 2009), muchas veces asociado con lógicas de resolución material de las comunidades que producen e intercambian bienes y servicios por fuera de la mecánica mercantil; y 3) niñas y niños también forman parte de una multiplicidad de actividades domésticas y de cuidado, en las que invierten sus esfuerzos y pueden ser conceptualizadas analíticamente como trabajo que produce valor transferible (valor de uso para la satisfacción de una necesidad). La participación infantil en actividades productivas de valor en sentido amplio engloba una diversidad de tareas, a veces poco sistemáticas, en una relación que varía en la planificación del tiempo e incluye prácticas que agrupan juego, sociabilidad y aprendizajes. Por toda esta complejidad descripta muchas veces estas labores no son admitidas desde la propia perspectiva infantil (o familiar) como trabajo, lo que habilita el desafío investigativo de explicar lo social "con" y "contra" las voces de los actores.

La anterior sistematización vislumbra que la resolución de lo que es considerado del ámbito de lo privado convive (no sin tensiones) con la lógica del mercado. Esto es, la producción de valor de uso en ocasiones se enlaza y en otras escapa a la producción de valor de cambio, así como también las esferas de satisfacción simbólica y afectiva ingresan (y se distancian) en la arena de los intercambios económicos. En este sentido, resulta clave la advertencia de Zelizer (2009) acerca de las limitaciones de pensar el trabajo infantil en términos de mundos hostiles. Este enfoque de "mundos hostiles" plantea que el orden social se organiza alrededor de principios contrapuestos e incompatibles. Esta perspectiva, criticada por Zelizer, se basa en el supuesto de que la actividad económica racional y las relaciones personales constituyen órbitas diferentes, una de cálculo y eficiencia, la otra de sentimientos y solidaridad. A su vez, sostiene que el contacto entre ambas esferas resulta en contaminación y desorden: la racionalidad económica corrompe la intimidad, y las relaciones íntimas obstaculizan las actividades económicas. Así, para la autora, es 
necesario enfocar en el trabajo relacional desplegado por los sujetos para producir distinciones que permitan mantener la ilusión de la gratuidad emocional y la objetividad de la vida económica.

Desde nuestra perspectiva, la resolución de la vida, y no sólo en términos económicos y de supervivencia (Fonseca, 2005), se conecta con otros aspectos como los afectivos, los recreativos y los de socialización (Frasco Zuker, 2016; Gorbán, 2014; Padawer, 2010; Rausky, 2009b). Niñas y niños juegan y trabajan, pasan de una actividad a otra, las re-significan y también las significan con categorías dominantes ingresando en los procesos de reproducción social. Las lógicas prácticas (Bourdieu, 1979) infantiles son más o menos improvisadas, no siempre calculadas, contradictorias y superpuestas, pero no por eso menos estratégicas (Fatyass, 2020).

En ocasiones, niñas y niños participan de relaciones de producción en las que generan un excedente de valor que no reciben por su tarea ni por la inversión de sus fuerzas productivas. Incluso obtienen mucho menos que cualquier otro sujeto atrapado en la contradicción capitalista entre capital-trabajo. Niñas y niños producen plusvalía, expresión monetaria del valor que el trabajador asalariado crea por encima del valor de su fuerza de trabajo; plustrabajo que asegura la acumulación capitalista y la mera subsistencia del sujeto trabajador. Por tanto, niñas y niños forman parte de la reproducción social soportando condiciones de explotación que llegan a ser extremas pues los afectan de múltiples formas y reducen notablemente el margen de autonomía. Aquí ubicamos aquello que la OIT define como "peores formas de trabajo infantil", entre ellas la esclavitud, la trata de niñas y niños, la reducción a servidumbre, el trabajo forzoso, la explotación sexual infantil, entre otras.

En otras circunstancias niñas y niños producen valor de uso, sobre el cual tienen más capacidad de decisión (no siempre reflexiva) acerca de la dirección de esa actividad de transformación. Esta puede estar relacionada con necesidades más biológicas, como comer, hasta más simbólicas, como el ocio y la estética corporal Este tipo de producción de valor transferible y sobre el cual niñas y niños tienen margen de agencia, puede desarrollarse incluso en contextos de desigualdad social, como en el caso de nuestras investigaciones.

Si bien resulta central establecer distinciones entre las diferentes formas de participación infantil en actividades productivas (no es lo mismo en el marco familiar que en una empresa explotadora, ni es lo mismo una jornada de 
trabajo extenuante que una jornada de pocas horas, entre otros factores), lo que queremos destacar es que niñas y niños forman parte activa de dichas relaciones sociales. Por tanto, acumulan capitales, recursos valorados, saberes legados y re-definidos, producen otros bienes y son capaces de reconvertir los capitales que portan en otros, en aras de solventar su reproducción e integración social, con relativa autonomía de sus núcleos familiares; aún cuando toda práctica de trabajo infantil impacte en la vida familiar.

Incluso niñas y niños son portadores de un capital simbólico que les pertenece en su condición infantil. Esto es, la pobreza infantil moviliza preocupaciones y acciones sociales y estatales particulares, el "niño en situación de pobreza" es un personaje social visible y digno de conmiseración o de atención. Por su parte, el enfoque de derechos provee de las narrativas dominantes para organizar y gestionar la protección de la infancia actual, ofrece espacios de maniobra (Haney, 2002) y lenguajes con que niñas y niños dotan de sentido sus experiencias y articulan sus demandas (Fraser, 1991). Es así un recurso relevante del que niñas y niños hacen uso estratégico.

Pero además, ellas y ellos participan en actividades productivas en sus territorios y van acumulando y reconvirtiendo capitales. Por ejemplo, cuando niñas y niños de clases populares forman parte de las organizaciones territoriales no sólo las/os hace partícipes de una experiencia política que les abre un abanico de recursos y lazos, sino que su inclusión legitima y sostiene las acciones de dichas agrupaciones. En este sentido, niñas y niños tienen la capacidad de otorgar valor a circuitos, espacios y relaciones (Zelizer, 1994).

En esta discusión, nos parece relevante recuperar algunos/as autores/as (Glockner, 2014; Noceti, 2011; Padawer, 2010; Rausky, 2009b) que diferencian conceptualmente entre la incorporación de las/os niñas/os a las actividades productivas del grupo doméstico y el trabajo infantil propiamente dicho. La primera sería condición para la transmisión de un patrimonio de saberes y la construcción de sucesores en la actividad desarrollada por los adultos del grupo doméstico, y se vincula con las expectativas de formación para la vida laboral de las unidades familiares, mientras que el segundo implica la venta de la fuerza de trabajo y la consecuente extracción de un plusvalor por parte del adulto, situaciones de riesgo y con escasas posibilidades de aprendizaje de un oficio o habilidades (Neves, 1999 apud Padawer, 2010; Sousa, 2004 apud Padawer, 2010). A partir de estas definiciones, y en especial en relación a la 
primera, los/as autores/as resaltan de qué manera la incorporación de niñas y las niños en tareas productivas no implica la reproducción de los circuitos de pobreza y desigualdad sino, por el contrario, amplía la estructura de oportunidades de las futuras generaciones (Macri, 2005 apud Padawer, 2010; Novacovsky, 2001 apud Padawer, 2010).

Junto con Padawer (2010) enfatizamos la relación familia-niño/a productivo (Llobet, 2012) para entender los circuitos en los que niñas y niños despliegan prácticas que producen un valor social significativo para la reproducción familiar (más que individual), posibilitado por un acervo de saberes que germina dentro del propio espacio doméstico. Coincidimos con su mirada en relación a admitir y visibilizar esta trama de producción y transmisión de conocimiento que suele ser vedada por las perspectivas abolicionistas sobre el trabajo infantil. En palabras de la autora:

la normativa nacional e internacional que protege a los niños del trabajo infantil opera como un obstáculo para reconocer estas experiencias que la ley prohíbe de manera general. La afirmación de que los niños deben estar en la escuela y los adultos en el trabajo limita las posibilidades de los maestros de incorporar las experiencias formativas que los niños llevan adelante fuera de la escuela, y los adultos miembros de las unidades domésticas tampoco pueden reconocerse como parte de un proceso educativo relevante para los niños. (Padawer, 2010, p. 364).

En un ejercicio análogo al que la autora hace con relación a los planteos de la OIT, quisiéramos colocar una arista sobre la temporalidad al aporte que realiza Padawer en relación con las capacidades de acción y conocimiento de niñas y niños. En contextos de desigualdad social persistente, como es el caso de nuestros campos de estudio y como señalan Rausky y Leyra Fatou (2017), se tensa y complejiza la temporalidad infantil vinculada a formas de resolución de la pobreza que, a su vez, tienen lugar en determinados espacios tales como la calle, la ciudad, los mercados y las instituciones. Niñas y niños circulan por estos espacios y establecen allí distintos tipos de interacciones que difieren de la lógica familiar, en la cual se encuentra una intencionalidad a futuro marcada por la transmisión de saberes por parte de los adultos. Sostenemos, entonces, que se trata más bien de un saber hacer y actuar de niñas y niños que van creando valor a medida que transitan por determinados contextos y en 
distintas temporalidades, por ejemplo, salir a jugar por el barrio puede habilitar oportunidades para conectar con otros, resolver el ocio y obtener recursos.

Por otra parte, a partir de los hallazgos de nuestras investigaciones, nos interesa introducir dos aspectos significativos para los estudios de infancia. Por un lado, que hay diversas prácticas productivas desarrolladas por niñas y niños de clases populares guiadas por sus propias intencionalidades y muchas veces a espaldas de las y los adultos/as. Ello permite discutir complementariamente la idea extendida en los contextos de pobreza acerca de que los padres y las madres son quienes mandan a sus hijas/os a trabajar y que deberían entender que vulneran los derechos de estas/os, como dicen los programas estatales de erradicación del trabajo infantil.

Por otro lado, la segunda aportación de este trabajo procura llamar la atención sobre el carácter singular de las prácticas infantiles, su relativa independencia de la estructura doméstica y sus clivajes derivados de la/del niña/o concreto que las realiza. En efecto, incluso en el seno de una misma unidad doméstica hay niñas/os que trabajan mientras que otras/os no, y a la vez, las tareas asignadas o permitidas a unos y otros se distribuyen a partir de una compleja y situada combinación de decisiones en las que pesa sobre todo la edad cronológica, la valoración de las capacidades y habilidades de la niña o del niño y una compleja trama de criterios morales y sociales en torno a lo aceptable en función del género y la edad.

Recapitulando en los aportes de Fonseca (2005), Zelizer (2009) y Williams (1997), con los otros mencionados, nuestro enfoque sobre el objeto de estudio permite desestabilizar prejuicios y fronteras que suponen espacios, esferas y temporalidades discontinuos que en nuestros campos no vemos tan tajantes. Por el contrario, encontramos que en determinados recortes empíricos el trabajo se conecta con el juego, con lo doméstico, lo institucional, lo territorial (el barrio y la ciudad); lo público y lo privado; y lo moral, lo afectivo y lo económico conviven (no sin conflictos).

En síntesis, a partir de la puesta en común y de los matices hasta ahora desarrollados sobre algunos aspectos que aportan a este campo de debates, afirmamos el carácter situado de la agencia y el sentido contextual (Frasco Zuker, 2019) de la participación de niñas/os en actividades productivas.

A continuación, profundizamos estas discusiones teóricas desde datos construidos en nuestras investigaciones referidas a experiencias infantiles en 
contextos de pobreza, especialmente en barrios periurbanos de Colonia Wanda (Misiones) y en barrios populares y en espacios institucionales de Villa María (Córdoba). Allí enfocamos prácticas de trabajo y de cuidado relacionadas con niñas y niños que venden piedras preciosas, salen a pedir o cuidan autos, mientras se cuidan a sí mismos y a otras/os.

\section{Formas de agencia infantil situada en Misiones y Córdoba, Argentina}

\section{Niñas/os que venden y cuidan}

La investigación etnográfica llevada a cabo en dos barrios periurbanos de Colonia Wanda (Misiones) permite iluminar las discusiones mencionadas. Su objetivo general fue caracterizar las experiencias de trabajo durante la infancia en distintas generaciones mediante una muestra intencional de unidades domésticas, considerando las relaciones sociales y el contexto social e histórico en que tuvieron y tienen lugar.

Dicha investigación tomó como antecedente un estudio realizado en la misma zona, que propuso comprender el trabajo de mujeres y niñas/os en minería informal como una de las consecuencias del aumento exponencial de las superficies reforestadas del Alto Paraná misionero, pues constituía una alternativa económica para la "población desplazada del trabajo rural" (Mastrangelo, 2006, p. 135). Partiendo de esa caracterización, se buscó profundizar específicamente en los sentidos que los sujetos le dan al trabajo (Gorbán, 2014), incluyendo a niñas y niños como interlocutores válidos (Szulc, 2006), así como en las distintas formas de producción de valor por parte de ellas/os, sin limitarse a la extracción y venta de piedras preciosas. Encontramos así que la extracción y posterior venta de piedras preciosas a turistas que van hacia Wanda para visitar su principal atractivo turístico (las minas) es una práctica vigente, que además constituye un problema (Fonseca; Cardarello, 1999; Fraser, 1991) para el estado municipal. ${ }^{1}$ No obstante, identificar a esas/os niñas/os meramente como "vendedoras/es" o como "niñas/os trabajadoras/es" no

1 Principalmente porque se trata de niñas y niños menores de 16 años, que es la edad mínima de admisión al empleo en Argentina. Además por la visibilidad que adquiere este tipo específico de trabajo infantil, llevado a cabo en el espacio público de ciudades por las que transitan turistas. 
explica aspectos sustantivos de su experiencia. El trabajo de campo etnográfico permitió evidenciar que el trabajo infantil de venta de piedras desplegado en el marco de relaciones familiares involucra dimensiones materiales pero también afectivas y morales, y refuerza y transforma lazos sociales. Asimismo, aportó elementos para discutir la sospecha moral que pesa sobre las familias de estas niñas y niños acerca de que "los mandan a vender y mendigar". Si bien la comercialización de piedras es para muchas familias una posibilidad de obtener dinero en un contexto de condiciones de vida y trabajo precarias, es más que una respuesta a tales circunstancias o un último recurso para sobrevivir. Las interpretaciones de madres, padres o incluso de las/os propias/os jóvenes ${ }^{2}$ que han llevado a cabo esa actividad económica durante su niñez acerca de las "ventajas" que tiene frente a otros trabajos formales pero "esclavos" (cosecha de yerba mate, peón forestal, empleado/a en local), muestran que es además generadora de tramas de sociabilidad. Posibilita estar cerca de las/os hijas/os o amigos mientras se vende, compartir recursos, tiempo y eventualmente viajes a Puerto Iguazú (en períodos de temporada alta de turismo) entre vecinos que también se dedican a eso y asimismo permite decidir cómo organizar el tiempo sin depender de un horario fijo de trabajo.

El tiempo y el espacio de trabajo infantil se articulan con el tiempo de juego y con el espacio doméstico. Mientras que niñas y niños están en la calle (a contraturno del horario escolar) a la espera de que pasen turistas, juegan entre sí y en muchas ocasiones el lugar de venta es la calle de sus propios hogares, lo cual posibilita a sus madres y padres verlas/os constantemente. Más aún, el juego coincide con la actividad económica que llevan a cabo: si no logran vender, algunas/os niñas/os más "caraduras" -como refieren localmente- piden galletitas a las/os visitantes mientras las/os otras/os niñas/os se burlan. Así, lejos de tratarse de mundos hostiles (Zelizer, 2009), esta forma de participación infantil en actividades productivas conecta las esferas de lo familiar, lo económico y lo recreativo. A diferencia de gran parte de la literatura sobre trabajo infantil callejero en grandes ciudades, en el contexto de estudio las calles son más bien un espacio cotidiano que conforma un continuum con la propia casa, desafiando y re-trazando las fronteras entre lo público y lo privado.

2 Se incorporaron al análisis las interpretaciones de jóvenes que trabajaron durante su niñez para dar cuenta de la densidad histórica de los sentidos asociados a esa experiencia. 
Desde la perspectiva de las/os jóvenes que trabajaron durante su niñez, estar en la calle vendiendo junto a pares "era divertido" y a la vez un espacio y tiempo en el que "nadie te decía qué hacer", como sí sucedía cuando estaban en la casa y a pedido de las/os adultas/os tenían que ordenar su ropa o barrer. Ahora bien, esto no obsta su capacidad para comprender y caracterizar situaciones en las que aún haciendo lo mismo (vender piedras en la calle) eran explotados y sometidos a situaciones de violencia. Lejos de naturalizar tales situaciones, como sugiere mucha bibliografía sobre el tema, encontramos que las/os niñas/os identifican formas "duras" de trabajo en el marco de sus familias y las contraponen a otras en que tienen autonomía para tomar decisiones: la expresión "así sí me gusta trabajar" da cuenta de ello. Complementariamente, tal distinción permite visibilizar que en las familias no solamente hay cooperación sino también relaciones de conflicto y poder.

La realización de actividades productivas por parte de niñas y niños se inscribe en lógicas familiares según las cuales "hacer algo" es valorado moralmente porque permite el sostenimiento de la unidad doméstica. En este sentido, el circuito del dinero obtenido por medio de la venta de piedras preciosas revela algunas de sus especificidades vinculadas a la edad, a las relaciones intergeneracionales y al género. Ese dinero es centralizado por la madre y separado para gastos específicos, tales como zapatillas o bien compra de alimentos que no se consumen de manera habitual (pizza, milanesas) y constituyen un momento especial. Este circuito monetario muestra por un lado el entrelazamiento de lo íntimo y afectivo y lo económico así como también permite reforzar el hecho de que son principalmente las mujeres adultas quienes deciden en qué se gasta el dinero de las/os hijas/os. Esto evidencia responsabilidades generizadas en la organización de la economía doméstica en sectores populares (Roig, 2015; Wilkis; Partenio, 2010) y a su vez expresa que ese dinero tiene "usos" vinculados con lo que Zelizer denominó el trabajo relacional. Esto es, el dinero aportado por las ventas realizadas por niñas y niños tiene un destino vinculado con sus necesidades prácticas o emocionales y en tal sentido su uso confluye en la construcción de modalidades de cuidado: que las madres decidan usar el dinero ganado por las/os niñas/os en zapatillas o pizzas es una manera de construir vínculos de cuidado. Estas distintas formas de participación de niñas y niños en actividades productivas manifiestan, entonces, cómo se entrecruzan prácticas productivas, dinero, solidaridad y conflictos en los vínculos familiares 
y permiten sostenerlos. Coincidimos con Zelizer (2005 apud Llobet, 2012) respecto a que los sentidos y efectos del trabajo infantil no están aislados sino que constituyen una interacción social vital.

En la investigación realizada en dos barrios de clases populares de Villa María, una ciudad intermedia de la provincia de Córdoba, hallamos que la resolución de la vida por parte de algunos niños, especialmente, varones, enlazaba algunas lógicas de agencia con prácticas de cuidado de autos. Estas prácticas ponían en evidencia que, en el barrio, conseguir dinero no se asociaba directamente a satisfacer situaciones materiales de vida, sino que mientras los niños trabajaban se desplegaban formas de sociabilidad generizadas y autogestionaban el tiempo libre.

Al conseguir dinero los niños satisfacían necesidades tales como comprarse ropa o zapatillas, "tomar la coca", ${ }^{3}$, en ocasiones, contribuir a la canasta familiar. Pero además el trabajo tenía que ver con una forma particular de transitar la condición infantil y la vida en el territorio. Los niños, a excepción de las niñas, trabajaban sin la dirección y la autorización explícita de los adultos de la familia, que desconocían muchas veces la dinámica que tomaba el cementerio cuando era intervenido por las prácticas infantiles de cuidar autos de los visitantes estacionados en las inmediaciones.

A diferencia de las divisiones tajantes entre lo educativo y lo económico que aflora en algunos enfoques sobre trabajo, la mayoría de los niños cuidadores de autos iban a la escuela y trabajaban, combinando ambos tiempos y espacios. Este trabajo no significaba salir del territorio barrial, sino que se resolvía dentro de un espacio conocido y con un grupo de compañeros y/o amigos. Sólo algunos trabajaban en las afueras del vecindario, limpiando vidrios, muchas veces con hermanos adolescentes o jóvenes, pues el acceso y permanencia en ese escenario estaba condicionado por la edad (eran niños mayores) e implicaba más exposición y gasto de tiempo y energía.

Los niños, al referirse a estas experiencias en las entrevistas realizadas, expresaron y reafirmaron su lugar como trabajadores. Así, si bien manifestaron que ir a cuidar autos era un tiempo para estar con amigos, compartir y ayudarse entre sí (dividiendo las tareas, incluso los recursos), de todos modos,

3 Esta expresión hace referencia al consumo de una bebida gaseosa. 
cuidar autos no era un juego. En efecto, los niños dejaban en claro que no estaban jugando, incluso se esforzaban en sus relatos por demostrar la importancia moral y social de su actividad, en un intento de visibilizarla y justificarla ante una mirada adulta que, en distintos escenarios, suele impugnar estas prácticas.

Las esferas del ocio y la resolución económica pueden cruzarse analíticamente, como advierte Zelizer (2009) sumado a que los propios niños combinaban en sus experiencias "cuidar autos" y "pasarla bien". Cuidar autos se manifestaba desde el punto de vista infantil como una responsabilidad asumida y una actividad socialmente significativa. Así los niños se diferenciaban a sí mismos de los jóvenes que limpian vidrios en la ciudad que, en el caso de Villa María, suelen estar "mal vistos", tanto desde los medios y la opinión pública como desde los funcionarios y agentes del Estado municipal. Estos niños se distanciaban también de niños o jóvenes de otros barrios que realizan malabares en las esquinas, considerando que esa forma de conseguir dinero era ilegítima pues "molestaban", reafirmando el valor social de su propia tarea. Decían que si ellos no estaban en el estacionamiento o en la calle, si no estaban "ahí", podían "ocurrir cosas" con los autos, ya sea robos o, en sus interpretaciones, los adultos podrían confundirse y marcharse en un auto equivocado. Esta tarea los convertía entonces en una especie de veladores del orden social en pos del bienestar adulto. La justificación del trabajo infantil en este caso se inscribe en una explicación que los propios niños necesitan dar a sus prácticas para validarlas socialmente y construir diferenciaciones y jerarquías morales entre las distintas tareas llevadas adelante por diversos grupos de niños, así como jerarquías sociales entre tales grupos.

Por su parte, las niñas de este barrio en particular no participaban de la dinámica de cuidar autos, pero expresaban con enojo en las entrevistas el deseo de hacerlo, para poder independizarse de realizar tareas y/o cumplir mandados y mandatos familiares. Ellas recibían dinero de sus familias por cuidar hermanas/os o primas/os, "ir a comprar" o ayudar en la casa, pero dicho monto era escaso y, a veces, no obtenían nada por tales tareas domésticas. Esto les dificultaba la independencia económica y social que decían no poseer, a diferencia de los niños de su edad.

En definitiva, el trabajo infantil en este último caso reproducía la división sexual del trabajo, pues las chicas no podían ingresar en el terreno de "los cuida autos", ni tampoco eran invitadas a "tomar la coca" con la plata que los chicos 
conseguían, aunque formaran parte del mismo grupo de pares, reforzándose la doble subalternidad de las niñas: por su edad y por su género, su inclusión en prácticas de trabajo se halla limitada y restringida, no sólo por parte de los adultos sino por los propios niños.

\section{Niñas/os que piden}

Además de los mencionados casos de niñas/os que vendían piedras preciosas y cuidaban autos, hallamos tanto en Wanda como en Villa María prácticas de limosneo realizadas en la calle y en el marco de un taller de educación popular en la segunda localidad. Estas estrategias incluían diferentes dimensiones en las que nos detenemos posteriormente: "pedir" variaba según situacionalidades. Esto se hacía en la calle de un modo más espontáneo o en contextos institucionales donde las negociaciones con los adultos demandaban otras formas y tiempos. Las/os niñas/os se veían involucrados en el limosneo hasta los 14 años aproximadamente; eran justamente los varones aquellos que "pedían" en la calle, mientras que "pedir en las instituciones" era una práctica que atravesaba ambos géneros.

Estas diversas prácticas infantiles para conseguir bienes significaban múltiples formas de inscribirse en lo territorial y en los vínculos con los otros, combinando relaciones personales, familiares y con los agentes institucionales, configurando así auténticos actos de producción de valor (político, afectivo, social y material). De tal modo, las relaciones afectivas entre niñas/os y agentes institucionales permitían construir distinciones entre "pedir en el taller" y "pedir en el barrio" (o incluso en la ciudad).

"Pedir en el marco de las instituciones", ya sea en el taller de educación popular o en el marco de programas estatales, a veces activaba por parte de niñas y niños relatos de victimización y presentaciones de sí como "pobres" (Fassin, 2004) que justificaban los pedidos de recursos materiales y otros que circulaban por estos contextos.

Por su parte, las edades para "salir a pedir" y vender en los territorios variaban, pero alrededor de los 14 años (aproximadamente) se solían retirar de estas tareas dado que, a partir de esa edad, les "da vergüenza". De tal manera, comenzaban a usar otras redes para obtener bienes en lo amplio de la ciudad y/o llevaban adelante prácticas de trabajo asalariado formal y/o informal como 
"changas". Sostenemos así que el "salir a pedir" y vender en la calle se asocia a una etapa de la vida y dejar de hacerlo marca un pasaje etario.

En general las niñas no se veían implicadas en estrategias territoriales de limosneo para conseguir dinero, pues solían recibir plata del grupo de parentesco y sólo declaraban administrarla para "sus cosas", aunque sí participaban activamente de los intercambios de recursos en los marcos de la vida institucional.

Asimismo, encontramos diferencias en las formas de obtener recursos entre los hermanos varones, porque toda práctica transmitida (de "los niños más grandes" a "los más chiquitos"), también es modificada y depende de las condiciones contextuales. Algunos niños presentaban personalidades más carismáticas que les habilitaban un abanico de opciones y relaciones para obtener recursos, otros sólo "salían a pedir" con parientes o amigos y acompañaban pero no hablaban con los adultos interlocutores, e incluso era posible encontrar en una misma familia que un niño tomara el lugar de proveedor de recursos mientras otro se desentendía de esta labor. De esta manera, "pedir en la calle" suponía ir sosteniendo, sin mucha proyección, una red de contactos donde ir a buscar recursos (algún vecino o en algún negocio); capital social que cultivaban las propias prácticas infantiles.

Mientras solicitar recursos en las instituciones demandaba determinada planificación por parte de los niñas y las niños, en principio asistir al lugar en el momento en que se distribuían los recursos, conocer a los agentes estatales y tener buenos vínculos con ellos, las interacciones con vecinos en el barrio o con desconocidos en la calle enlazaba otro tipo de vínculo más individual, improvisado y contingente. Otras veces, las redes de solidaridad entre grupos de parentesco ampliado o entre algunos integrantes del vecindario, tejían sentidos conflictivos donde los niños que "pedían" solían ser definidos como problemáticos desde la mirada adulta.

En definitiva, las/os niñas/os de sectores populares hacen un uso extensivo del barrio, establecen relaciones con amigos, vecinos y grupos de parentesco en el territorio y se relacionan con las instituciones produciendo vínculos afectivos e intercambios materiales con grupos de otras clases y edades.

"Salir a pedir", en la calle o en las instituciones, se enredaba con formas de socialización según géneros y edades, con modalidades de usar el tiempo, con maneras de transitar los espacios y simbolizar la vida y no sólo con la subsistencia material. 


\section{Cuidado: más allá del trabajo no pago}

En este apartado retomamos algunos aportes fundamentales de estudios feministas centrados en el cuidado que se vinculan con la problematización del trabajo e incorporamos en este debate algunas particularidades relacionadas a nuestra preocupación por las infancias de sectores populares.

Acordamos con la premisa básica y no por eso menos relevante del feminismo acerca de que el cuidado es trabajo no pago (England, 2005 apud Zibecchi, 2014; Faur, 2014), muchas veces menospreciado, en el que participan activamente niñas y niños. Aquí se observa una división sexual del trabajo pues las niñas sostienen sistemáticamente prácticas de cuidado, actualizando la ideología maternalista y ejercitando desde temprana edad una disposición social a cuidar. Aunque sean mayoritariamente las niñas y mujeres adultas quienes desplieguen prácticas de cuidado, esto no debe desembocar en asumir linealmente la opresión intrínseca de estas prácticas o la retradicionalización de los roles de género (Llobet; Milanich, 2014). Desde una lectura feminista el confinamiento de las mujeres al espacio doméstico debe ser discutido en tanto constituye una fuente de opresión y desigualdad respecto de los varones que supone una sobrecarga de trabajo no remunerado y desvalorizado. No obstante ello, no debería perderse de vista que tal planteo teórico no necesariamente excluye la consideración de la agencia involucrada en las tareas de cuidado.

Los distintos tipos de cuidado, como todo trabajo, adquieren significado en contexto y se valorizan en las interacciones particulares, en cuyo marco la evaluación moral de los agentes participantes (las/os propias/os niñas/os, familias o agentes del Estado) van corriendo la frontera sobre qué es cuidar bien o mal y cuándo el cuidado es estrictamente un trabajo o no. Así, el cuidado es producción de valor en tanto trabajo, ya que trama una serie de prácticas, sentidos y relaciones desde las que se procesan el cuerpo propio y el ajeno para proteger la vida (con y a veces contra la voluntad del otro).

Coincidimos con Martín Palomo (2008, p. 20) cuando sostiene que el cuidado posee distintas dimensiones que no son adecuadamente captadas por estudios que se focalizan fundamentalmente "en la denuncia y en el análisis de la exclusión, la discriminación y la subordinación”. Propone por ello una herramienta teórica a la que denomina la domesticación del trabajo que apunta a registrar el valor social y los aspectos materiales, morales y afectivos 
que compromete el cuidado. Así, esta autora entiende al cuidado como un trabajo contingente que participa directamente en el mantenimiento de la vida del otro, de asistir a sus necesidades básicas y/o de promover su autonomía progresiva (Martín Palomo, 2008; Molinier, 2012).

Introducir los temas de cuidado como trabajo no pago en la condición infantil, desestabiliza, al igual que planteamos en el apartado anterior, una idea hegemónica según la cual la infancia es vulnerabilidad y dependencia de los adultos. En contraposición, al interrogar las prácticas cuidado se manifiesta el papel activo de niñas y las niños en la vida social y se desafía la idea de infancia como etapa marcada únicamente por la felicidad, el tiempo de juego y la diversión, tal como han afirmado algunos referentes de los llamados "Childhood Studies".

Niñas y niños se desenvuelven con cierta autonomía respecto a los adultos en el marco de restricciones y responsabilidades (Ibarra; Vergara del Solar, 2017). En este sentido, la incorporación de niñas y niños a actividades de cuidado se vincula con las desigualdades de clase, edad y género y a su vez implica la intersección de dimensiones afectivas, morales y económicas (frecuentemente invisibilizadas).

\section{Entre la protección y la acción directa sobre el cuerpo del otro}

Las/os propias/os niñas y niños participan de vínculos que enlazan cuidado y protección, sobre sí mismos y respecto a los pares y/o a los adultos, lo que expresa su capacidad de agencia para sostener la vida y tensiona el ideario adultocéntrico que las/os considera como frágiles y dependientes del amparo adulto (Llobet, 2009, 2012). Admitir que niñas y niños son agentes de cuidado, son agentes morales (Mayall, 2002), no significa invisibilizar que pueden estar expuestos a situaciones de violencia material, simbólica, física y/o sexual.

Niñas y niños, incluso en condiciones de subordinación material, se revelan entonces como agentes capaces de resguardar a los demás. En nuestras investigaciones, el cuidado estaba referido, especialmente, a las/os hermanas/os menores o las/os "más pequeñas/os" del grupo de pares (aunque no exclusivamente). Niñas y niños llevaban a cabo minuciosas rutinas éticas (Mayall, 2002) desarrolladas para producir la vida ordinaria: atar cordones, abrigar, asegurar y distribuir los alimentos, compartir juegos, intervenir en conflictos poniendo 
el cuerpo, etc. La producción de los cuidados se conecta entonces con la circulación de las afectividades y con otras redes de intercambios en y entre grupos.

Los cuidados registrados significaban, muchas veces, compartir tiempo y espacio con las/os "más pequeñas/os", por tanto, implicaban también formas de sociabilidad (Hernández, 2017) a medida que se ampliaban las espacialidades y se diversificaban las actividades. Son muchas las escenas donde apuntamos esta capacidad de agencia de niñas y niños para solventar el bienestar de otros o incluso el personal, tal como vienen planteando otras investigaciones (Niñez Plural, 2019).

Si bien en nuestros trabajos de campo niñas y niños se veían comprometidos en el cuidado de hermanas/os menores, se mantenía cierta división sexual del trabajo: los varones solían ceder más rápido ante las intervenciones adultas para dirigir los cuidados, las mujeres en cambio mostraban más disposición hacia esta tarea o eran más reacias a compartirla con los varones de su edad; se veían así convocadas al cuidado, a estar con bebés, incluso como juego que enlazaba, en el mismo acto, una especie de aprendizaje y de ejercicio físico (asociado con la fuerza de los brazos) necesario para un lugar que parecía destinado en el futuro.

El cuidado se expresaba incluso en amenazas entre grupos de pares, hermanas/os y mediante situaciones de violencia física, en situaciones muy específcas. En ocasiones, en los contextos populares de Villa María, entre hermanas/os se defendían de ataques externos expresando "hacer cagar"4 a otro, si alguno de la familia era ofendido o golpeado; el "hacer cagar", muchas veces, ponía distancia, recordaba el lugar de cada quien (y las solidaridades e intercambios) y no se consumaba, necesariamente, como un reto físico, sino más bien moral.

A propósito de la relación entre cuidado infantil y castigos físicos, explicitada en los relatos recuperados de las/os propias/os niñas y niños y en determinadas prácticas registradas, algunas investigaciones han mostrado cómo ambos niveles no solamente no resultan esferas excluyentes, sino que los castigos físicos son entendidos como una forma legítima de crianza de las/os hijas/os (Frasco Zuker, 2019; Llobet, 2009), no sólo en contextos de pobreza. En este sentido, en el cuidado cotidiano "conviven el amor y la violencia en asociación"

4 Esta expresión nativa hace referencia a una amenaza de golpear a otro. 
(Castilla, 2017, p. 48) o bien, el control y las relaciones de poder no pueden ser excluidas de la noción de cuidado (Llobet, 2009).

En nuestras investigaciones mostramos que algunos niños utilizaban la amenaza de pegar cuando no había adultos que lo supervisen y dirigían la práctica de cuidado hacia sus hermanas/os menores. Como por ejemplo un niño activaba recursos de los adultos apropiándose de la amenaza, pero usándola de un modo diferente al de su padre: ${ }^{5}$ el niño impulsaba esta sanción con sólo ver a su hermana bailando frente al espejo. Por otra parte, el ejemplo da cuenta de cómo las responsabilidades delegadas a las/os niñas/os varían según las edades y se despliegan en ciertos espacios. Esto es, en el espacio doméstico la diferencia de edades condiciona quién cuida y quién es cuidado: el hermano mayor debe cuidar a las/os hermanas/os menores en la casa. Sin embargo, esto también es situacional pues, en otros espacios y actividades no es la edad la que articula el cuidado, sino que suele primar el género. Así encontramos que muchas veces eran las niñas, no siempre mayores, quienes decidían sobre las actividades a realizar, cuándo regresar a la casa y eran ellas las que recordaban a los otros cómo "portarse bien".

En esta línea de análisis, generalmente los niños del grupo familiar eran los proveedores de los recursos, aquellos que salían "a pedir" dinero, a trabajar, mientras las niñas, no siempre las hermanas mayores, se encargaban de distribuir estos recursos, de administrarlos y de gestionarlos según el comportamiento que evaluaban en el resto del grupo familiar, además de decir cuándo y cómo compartirlo con otras/os niñas/os externos al grupo de parentesco. Trabajo y cuidado enfocados desde el clivaje etario y sus posibilidades de agencia complejizan entonces la generización de lo social. Recursos materiales y simbólicos, distinciones y jerarquías morales y sociales son transformadas, producidas o reforzadas por las tareas de cuidado y reproducción.

Niñas y niños son, por tanto, agentes capaces de defenderse y usar la fuerza física, así como de resolver situaciones conflictivas, compartir y gestionar recursos, sostener solidaridades entre grupos de pares y entre sus familias, proteger y brindar ayuda, haciendo más habitable y soportable las situaciones a las que se enfrentan en los contextos de desigualdad persistente en los que viven.

5 El padre amenazaba frecuentemente a sus hijas/os cuando se peleaban entre hermanas/os o no acataban alguno de sus pedidos. 


\section{Discusión: repensando las formas de agencia infantil}

En este artículo retomamos algunas dimensiones sobre diferentes prácticas de trabajo realizadas por niñas y niños, entre las cuales incluimos al cuidado, caracterizándolas como actividades productivas destinadas a sostener la vida propia y/o de otros, a partir de nuestras propias investigaciones en contextos de pobreza urbanos y turísticos en Argentina.

Sostuvimos que el trabajo infantil puede admitir diferentes formas conectadas con el espacio de reproducción familiar y que asimismo existen otras lógicas de trabajo en el mercado (asalariado o no) que condenan a niñas y niños (y a sus familias) a un profundo desamparo en condiciones de explotación. En relación con los hallazgos de nuestros trabajos de campo, encontramos que niñas y niños participan de una serie de actividades productivas en sentido amplio, con cierta autonomía relativa de los adultos, que producen valor social y complejizan las propias dinámicas de las estrategias de reproducción social familiar y del mercado. Consideramos, entonces, que niñas y niños son agentes capaces de habitar el mundo y de procesarlo estableciendo jerarquías morales y sociales en los procesos de socialización. Así como participan de estos procesos, las prácticas productivas de niñas y niños de clases populares interpelan al espacio de las políticas públicas destinadas a estas poblaciones, en tanto desafían límites entre lo legal y lo ilegal, la protección y el desamparo, y la autonomía y la dependencia, dimensiones que se juegan en el gobierno de la infancia.

En diálogo con el campo de debates sobre trabajo, cuidado e infancias en contextos de desigualdad social, hallamos que espacios territoriales distantes físicamente, se conectaban en términos sociales, morales y afectivos relacionados con las prácticas productivas realizadas por niñas y niños. En ambos contextos participaban de los arreglos familiares de reproducción social creando una compleja trama de criterios morales y sociales en torno a lo aceptable en función del género y la edad. Pero también tenían cierta independencia para gestionar su tiempo libre, circular por el territorio, establecer vínculos con otros grupos, formar parte de las redes institucionales que intervienen sobre la infancia, buscar, acumular y reconvertir capitales, así como en ocasiones decidir sobre las inversiones y usos de esos recursos. En suma, niñas y niños construyen mediante usos específicos de las tareas productivas y reproductivas, diferenciaciones morales así como jerarquías sociales en y entre grupos. 
En definitiva, procuramos colocar, desde lecturas críticas e investigaciones situadas, matices analíticos que enfatizan la complejidad de la temporalidad de las prácticas de niñas y niños que trabajan desde diversos derroteros y cursos de acción y en delimitados espacios. Este artículo nos convocó a escribir desde un interés epistémico, para comprender experiencias de vida particulares y formas de agencia situadas, pero más aún nos sentimos comprometidas políticamente en problematizar qué consecuencias conlleva el trabajo infantil. Si bien por un lado nos posicionamos junto con la OIT contra las "peores formas de trabajo", nos interesa seguir pensando cuáles serían las "mejores formas de trabajo" en que niñas y niños puedan ser reconocidos socialmente en su carácter pleno de agentes sociales, políticos y morales.

\section{Referencias}

BACHELARD, G. La formación del espíritu científico. Buenos Aires: Siglo Veintiuno, 1987.

BOURDIEU, P. La distinción: criterios y bases del gusto. Madrid: Taurus, 1979.

CASTILLA, M. V. Maternidad, cuidados y castigos en barrios marginales y vulnerables de Buenos Aires. Runa: Archivo para las Ciencias del Hombre, Buenos Aires, n. 38, p. 37-51, 2017.

DE LA GARZA TOLEDO, E. Hacia un concepto ampliado de trabajo. In: NEFFA, J. C.; DE LA GARZA TOLEDO, E.; MUÑÍZ TERRA, L. (comp.). Trabajo, empleo, calificaciones profesionales, relaciones de trabajo e identidades laborales. Buenos Aires: CLACSO, 2009. p. 111-140.

FASSIN, D. Entre las políticas de lo viviente y las políticas de la vida. Hacia una antropología de la salud. Revista Colombiana de Antropología, Bogotá, v. 40, p. 283-318, enero/dic. 2004.

FATYASS, R. Niña/o de la agencia infantil: espacios educativos y contextos de pobreza en Villa María, Córdoba. 2020. Tesis (Doctorado) - Universidad Nacional de Villa María, Villa María, 2020.

FAUR, E. El cuidado infantil en el siglo XXI: mujeres malabaristas en una sociedad desigual. Buenos Aires: Siglo Veintiuno, 2014. 
FONSECA, C. La clase social y su recusación etnográfica. Etnografias Contemporáneas, [s. l.], v. 1, n. 1, p. 117-138, 2005.

FONSECA, C.; CARDARELLO, A. Direitos dos mais e menos humanos. Horizontes Antropológicos, Porto Alegre, ano 5, n. 10, p. 83-122, maio 1999.

FRASCO ZUKER, L. Investigación etnográfica sobre experiencias de trabajo infantil en el noreste argentino. Revista Latinoamericana de Ciencias Sociales, Niñez y Juventud, [s. l.], v. 14, n. 2, p. 1205-1216, 2016.

FRASCO ZUKER, L. Cuidar a la gurisada: etnografía sobre trabajo infantil y cuidado en la localidad de Colonia Wanda, Misiones. 2019. Tesis (Doctorado) - Escuela Interdisciplinaria de Altos Estudios Sociales, Universidad Nacional de San Martín, San Martín, 2019.

FRASER, N. La lucha por las necesidades: esbozo de una teoría crítica socialista feminista de la cultura política del capitalismo tardío. Debate Feminista, Ciudad de México, v. 3, p. 3-40, marzo 1991.

GLOCKNER, V. Trabajo infantil y regímenes de gubernamentalidad: slums flexibles, ongs y producción de subjetividades en la India contemporánea. 2014. Tesis (Doctorado) - Universidad Autónoma Metropolitana, Ciudad de México, 2014.

GORBÁN, D. Las tramas del cartón: trabajo y familia en los sectores populares del Gran Buenos Aires. Buenos Aires: Gorla, 2014.

HANEY, L. Inventing the needy: gender and the politics of welfare in Hungary. Berkeley: University of California Press, 2002.

HERNÁNDEZ, M. Andar afuera. Un análisis de la experiencia infantil urbana en contextos socio urbanos de pobreza en La Plata, Provincia de Buenos Aires, Argentina. In: SIMPOSIO INTERNACIONAL ENCUENTROS ETNOGRÁFICOS CON NIÑAS, NIÑOS, ADOLESCENTES Y JÓVENES EN CONTEXTOS EDUCATIVOS, 4.; SIMPOSIO INTERNACIONAL DE INVESTIGACIONES CUALITATIVAS CON PARTICIPACIÓN DE NIÑAS, NIÑOS, ADOLESCENTES Y JÓVENES, 1., 2016, Foz do Iguaçu. Anales [...]. [S. l.: s. n.], 2017.

IBARRA, P.; VERGARA DEL SOLAR, A. Ser niño y niña en el Chile de hoy: la perspectiva de sus protagonistas acerca de la infancia, la adultez, y las relaciones entre padres e hijos. Santiago de Chile: CEIBO, 2017.

LIEBEL, M.; SAADI, I. ¿Erradicación del trabajo infantil o trabajo digno para niños trabajadores? Anotaciones al nuevo Informe Global sobre trabajo infantil de la OIT. Rayuela: Revista Iberoamericana sobre Niñez y Juventud en Lucha por sus Derechos, [s. l.], año 2, n. 4, p. 111-115, mayo/nov. 2011. 
LLOBET, V. Las políticas sociales para la infancia, la psicología y el problema del reconocimiento. Investigaciones en Psicología: Revista del Instituto de Investigaciones de la Facultad de Psicología, [s. l.], v. 14, n. 2, p. 73-94, 2009.

LLOBET, V. Una lectura sobre el trabajo infantil como objeto de estudio. A propósito del aporte de Viviana Zelizer. Desarrollo Económico, [s. l.], v. 52, n. 206, p. 311-328, 2012.

LLOBET, V.; MILANICH, N. La maternidad y las mujeres de sectores populares en las Transferencias Condicionadas de Ingresos. Un aporte al debate sobre el cuidado y las relaciones de género. Zona Franca, [s. l.], v. 22, n. 23, p. 58-69, 2014.

MACRI, M.; UHART, C. (comp.). Trabajos infantiles e infancias: investigaciones en territorio (Argentina 2005-2010). Buenos Aires: Stella, 2012.

MARTÍN PALOMO, M. T. "Domesticar" el trabajo: una reflexión a partir de los cuidados. Cuadernos de Relaciones Laborales, [s. l.], v. 26, n. 2, p. 13-44, 2008.

MARX, K. El capital: el proceso de producción del capital: tomo I. Buenos Aires: Siglo Veintiuno, 2017.

MASTRANGELO, A. Miserias preciosas: trabajo infantil y género en la minería artesanal. Misiones, Argentina. In: CASTILHOS, Z. C.; LIMA, M. H. M. R.; CASTRO, N. F. (org.). Gênero e trabalho infantil na pequena mineração sul-americana Brasil, Peru, Argentina, Bolívia. Rio de Janeiro: Cetem: CNPq, 2006, p. 135-151.

MAYALL, B. Towards a sociology for childhood. Buckingham: Open Univerity Press, 2002.

MILSTEIN, D. Y los niños, ¿por qué no?: algunas reflexiones sobre un trabajo de campo con niños. Avá: Revista de Antropología, Posadas, n. 9, p. 49-59, 2006.

MINISTERIO DE TRABAJO, EMPLEO Y SEGURIDAD SOCIAL (Argentina). Trabajo infantil prohibido. In: ARGENTINA.GOB.AR. [S. l.]: Gobierno de Argentina, 2020. Portal. Disponible en: https://www.argentina.gob.ar/trabajo/infantil/trabajo-infantil-prohibido. Acceso: 25 enero 2020.

MOLINIER, P. Ética e trabalho do care. In: HIRATA, H.; GUIMARÃES, N. Cuidado e cuidadoras: as várias faces do trabalho do care. São Paulo: Editorial Atlas, 2012. p. 29-43.

NIÑEZ PLURAL. Niñez, alteridad y cuidado: reflexiones para un campo en construcción. Desidades, [s. l.], año 7, n. 25, p. 48-58, 2019.

NOCETI, M. "Trabajo infantil rural" y "explotación infantil rural". Aportes antropológicos a la diferenciación de conceptos para el diseño de políticas de protección de derechos del niño en el sudoeste bonaerense. Papeles de Trabajo, [s. l.], n. 22, p. 58-73, 2011. 
NOVICK, M.; CAMPOS, M. El trabajo infantil en perspectiva. Sus factores determinantes y los desafíos para una política orientada a su erradicación. In: APARICIO, S. et al. (ed.). El trabajo infantil en la Argentina: análisis y desafíos para la política pública. Buenos Aires: Organización Internacional del Trabajo, 2007. p. 19-52.

PADAWER, A. Tiempo de estudiar, tiempo de trabajar: la conceptualización de la infancia y la participación de los niños en la vida productiva como experiencia formativa. Horizontes Antropológicos, Porto Alegre, ano 16, n. 34, p. 349-375, jul./dez. 2010.

RAUSKY, M. ¿Infancia sin trabajo o infancia trabajadora? Perspectivas sobre el trabajo infantil. Revista Latinoamericana de Ciencias Sociales, Niñez y Juventud, [s. l.], v. 7, n. 2, p. 681-706, 2009a.

RAUSKY, M. Trabajo y familia: el aporte de los niños trabajadores a la reproducción del hogar. Trabajo y Sociedad, Santiago del Estero, v. 11, n. 12, 2009b.

RAUSKY, E.; LEYRA FATOU, B. Estudios socio-antropológicos con niños y niñas trabajadores. Una apuesta reflexiva sobre dos experiencias en América Latina: México y Argentina. Papeles de Trabajo, [s. l.], n. 33, p. 53-63, 2017.

ROIG, A. Separar de si, separar para si: aproximaciones a las prácticas de ahorro domésticas en sectores populares urbanos argentinos. In: ROIG, A.; WILKIS, A. (coord.). El laberinto de las finanzas y de la moneda: nuevas perspectivas de los Estudios Sociales de la Economía. Buenos Aires: Biblos, 2015. p. 195-210.

SALLES, V. El trabajo, el no trabajo: un ejercicio teórico-analítico preliminar desde la sociología de la cultura. In: DE LA GARZA TOLEDO, E. (comp.). Los retos teóricos de los estudios del trabajo hacia el siglo XXI. Buenos Aires: CLACSO, 1999. p. 97-113.

SCOTT, J. Seeing like a state: how certain schemes to improve the human condition have failed. New Haven: Yale University Press, 1998.

SZULC, A. Antropología y niñez: de la omisión a las "culturas infantiles". In: WILDE, G.; SCHAMBER, P. (comp.). Culturas, comunidades y procesos urbanos contemporáneos. Buenos Aires: SB, 2006. p. 25-50.

WILKIS, A.; PARTENIO, F. Dinero y obligaciones generizadas: las mujeres de sectores populares frente a las circulaciones monetarias de redes políticas y familiares. $\mathrm{La}$ Ventana, [s. l.], n. 32, p. 177-213, 2010.

WILLIAMS, R. Marxismo y literatura. Barcelona: Editorial Península, 1997.

ZELIZER, V. Pricing the priceless child: the changing social value of children. Princeton: Princeton University Press, 1994. 
ZELIZER, V. La negociación de la intimidad. Buenos Aires: Fondo de Cultura Económica, 2009.

ZIBECCHI, C. Trayectorias de mujeres y trabajo de cuidado en el ámbito comunitario: algunas claves para su estudio. La Ventana, [s. l.], n. 39, p. 97-139, 2014.

Recebido: 27/01/2020 Aceito: 24/03/2021 | Received:1/27/2020 Accepted:3/24/2021 